\title{
Abnormal expression of FAK and paxillin correlates with oral cancer invasion and metastasis
}

\author{
Ming Song ${ }^{\varpi}$, Jiang $\mathrm{Hu}$ and Hai-Ying Quan \\ Department of Stomatology, Affiliated Hospital of Jilin Medical University, Jilin, 132013, China
}

Globally, the tenth most common cancer is the oral squamous cell carcinoma (OSCC) and the treatment strategy for improving of OSCC patients survival rate still remains a challenging one. Aberrant regulation of cell to extracellular matrix protein interactions leads to progression of human cancers. The focal adhesion kinase (FAK) and its downstream target paxillin have been implicated in cancer growth, migration, invasion and metastasis of different cancers. However, the clinical significance of FAK and paxillin in OSCC is not well characterized so far. In the present work, we showed that relative mRNA and protein expressions of FAK and paxillin are significantly higher in side population (SP) cells of OSCC cell line SCC-55. Concomitantly, the matrix metalloproteinase-11 (MMP-11) level is also significantly elevated in SP cells. The enhanced expression of paxillin is strongly correlated with increased chemoresistance, proliferation rate, migration and invasion potential of SP cells. In addition, inhibition of paxillin expression by RNAi makes SP cells more sensitive to chemotherapy drugs. Therefore, our results suggest that paxillin over expression might play a significant role in cancer progression, invasion and chemoresistance of OSCC.

Keywords: chemoresistance, focal adhesions, invasion, metastasis, paxillin

Received: 24 December, 2020; revised: 27 January, 2021; accepted: 05 February, 2021; available on-line: 16 April, 2021

घe-mail: mingsong1976@gmail.com

Acknowledgements of Financial Support: We thank the funding support provided by Jilin Medical University, Funding reference number: MJ13025180603-25.

Abbreviations: ECM, extracellular matrix; FAK, focal adhesion kinase; OSCC, oral squamous cell carcinoma; MMP-11, matrix metalloproteinase-11; SP, side population

\section{INTRODUCTION}

In worldwide, the tenth most common cancer is the oral squamous cell carcinoma (OSCC). Treatment includes standard surgeries, conventional chemotherapy and adjuvant radiotherapy for the patients at advanced metastatic stage (Bernier et al., 2004). Inspite of advanced early diagnosis and progressive treatment approaches, the average life span of OSCC patients are under 5 years at metastasis stage (Zini et al., 2010; Lin et al., 2016). Therefore, identification and development of new biomarkers are essential, which can be used as a prognostic factors for cancer progression, invasion and for the improvement of cancer treatment.

Focal adhesions are complex, large dynamic proteins, which links cytoskeleton of the cells to the extracellular matrix (ECM). Different proteins localize at focal adhesion site includes focal adhesion kinase
(FAK), paxillin, alpha-v beta-3 integrin and vinculin which controls cell adhesion and migration (Wolff et al., 1998). Loss of adhesion to the ECM is the major cause for cancer cell migration, invasion and metastasis. Paxillin is a signal transduction adapter protein, links actin filaments to the integrins at cell adhesion sites. Paxillin actively performs cytoskeletal remodelling and integrating multiple signals from ECM, which are crucial for maintaining cell morphology, cell spreading, motility, proliferation, apoptosis and angiogenesis (Du et al., 2016; Shekhar et al., 2017). Paxillin can acts as both docking site and substrate for various growth factors and oncogenic proteins ( $\mathrm{v}$-src, $\mathrm{v}$ crke, $B C R / A B L$ ) in order to interfere the regulation of normal cell adhesion process in cancer cells (Turner, 2000). Several studies in solid tumors proved that paxillin over expression are often associated with carcinogenesis and decreased patients survival rate (Tremblay et al., 1996; Vadlamudi et al., 1999; Rosanò et al., 2003; Jagadeeswaran et al., 2008; Chen et al., 2013). Particularly, increased expression of paxillin and its phosphorylated form are considered as one of the reasons for the poor curative effect of cetuximab due to apoptosis inhibition and accelerated cell survival rate (Jun et al., 1995; Chen et al., 2013; Du et al., 2016).

The second key factor involved in the regulation of ECM interactions (Schaller et al., 1995) are Focal adhesion kinase (FAK), a tyrosine kinase protein. FAK localized at focal contact sites and severs as a receptor for signalling pathways triggered by growth factors such as EGF, PDGF and others (Siege et al., 2000). Emerging evidences in cancer studies shown that activation of FAK potentially contributed for cell motility, proliferation and invasion in different cancers (Frisch et al., 1996; Aguirre et al., 2002). The cancer invasion and poor prognosis are correlated with over expression of FAK protein and fak gene copy number in cancer cells (Owens et al., 1995; Agochiya et al., 1999).

For invasion and metastasis, the cancer cells should get detached from the extracellular matrix (ECM) and enter in to blood and lymphatic systems ( $\mathrm{Su}$ et al., 2017). Matrix metalloproteinases (MMPs) are zinc based endopeptidases whose major function is the degradation of components and basement membranes of ECM. Enhanced expression of MMPs are often associated with different types of cancers and particularly MMP-11 is the most commonly observed in invasive human carcinomas such as breast, oral and ovarian carcinomas (Porte et al., 1995; Fiorentino et al., 2009; Hsin et al., 2017). Recently, MMP-11 was shown to be involved in promoting cell migration through the activation of FAK and Src pathway (Hsin et al., 2017). 
From these findings it is obvious that molecular abnormalities in turnover of focal adhesion components (paxillin, FAK) ultimately reflected to cancer invasion and metastasis. Therefore, these components should be subjected to intensive investigation to address the signaling pathways and other key molecular players involved in aggressive phenotypes and poor clinical outcomes. The purpose of our study is to evaluate the PXN and $F A K$ expression and its impact oral cancer progressions in established human oral cancer cell line SCC-55. We also investigated the possible relationship between paxillin expression and oral cancer cell progression.

\section{MATERIALS AND METHODS}

\section{Cell line and cell culture}

The oral squamous cell line SCC-55 (Grade-3; Mandibular region and recurrence tumor type) was cultured in T-125 Flasks or cell culture dishes with DMEM provided with $10 \%$ FBS and antibiotics such as Pencillin and Streptomycin. Cells were incubated in a humidified $5 \% \mathrm{CO}_{2}$ at $37^{\circ} \mathrm{C}$ with a supply of $95 \%$ air atmosphere. Upon confluency, cells were washed with $1 \times$ PBS and treated with $1 \mathrm{~mL}$ of Trypsin-EDTA $(0.25 \%-53 \mathrm{mM}$ EDTA) and suspended in 10\% FBS containing. From this suspension, cells were collected for corresponding experiments or $1 \mathrm{~mL}$ of cells were transferred to a new flask with fresh medium for further passages.

\section{Hoechst labeling and FACs sorting}

Experimental groups were assigned as a) Hoechst 33342 dye labeled $(n=3)$ and b) Drug treated group: Hoechst 33342 dye and verapamil treated $(n=3)$. Cells were grown on DMEM for 24 hours labeled with either Hoechst 33342 dye $(5 \mu \mathrm{L} / \mathrm{mL})$ or in combination with verapamil drug $(0.8 \mu \mathrm{L} / \mathrm{mL})$. Subsequently, cells were counterstained with propidium iodide (PI) of $2 \mu \mathrm{g} / \mathrm{mL}$. Finally, cells were resuspended in $1 \mathrm{~mL}$ of HBSS with $10 \mathrm{mM}$ HEPES and subjected to FACs sorting.

\section{Reverse transcriptase-polymerase chain reaction (RT- PCR)}

Total cellular RNA was extracted by using Qiagen RNA Kit. Biorad iCycler machine and the given protocol were used to perform RT-PCR. The primer sequences for GAP$D H, F A K$ and PXN were used as mentioned previously (Hong et al., 2012; Chen et al., 2013). The PCR parameters used are: Initial denaturation was set to $95^{\circ} \mathrm{C}$ for $60 \mathrm{~s}$ followed by denaturation at $95^{\circ} \mathrm{C}$ for $6 \mathrm{~min}$. Annealing was done at $58^{\circ} \mathrm{C}$ for $20 \mathrm{~s}$, extension at $70^{\circ} \mathrm{C}$ for $15 \mathrm{~s}$ and final extension at $70^{\circ} \mathrm{C}$ for $10 \mathrm{~min}$. This was repeated for 35 cycles. The quantified mRNA expression levels were adjusted with the GAPDH, used as a housekeeping gene. The values obtained from the average of the three independent experiments. Pearsons and Spearmans correlation were used to represent the values as a quantification graph.

\section{Cell transfections}

Cells were grown on 6 well plates with a range of $2 \times 10^{6}$ cells/well. For knockdown PXN expression, the small interfering RNA (siRNA) of $100 \mathrm{nM}$ concentration are incubated in Opti-MEM (InVitrogen) together with the $6 \mu \mathrm{L}$ of transfection reagent Lipofectamine ${ }^{\circledR}$ RNAiMAX (Thermofishers) for $20 \mathrm{~min}$ at RT. The reaction mix were added to the cells and incubated for
24-48 hours and cells were further analyzed for the phenotypes.

\section{Immunocytochemistry}

Cells grown on 12 well culture plates were fixed in 4\% PFA (Paraformaldehyde) followed by blocking in $1 \%$ BSA-TBS with RNase $(10 \mu \mathrm{L} / \mathrm{mL})$ for $1 \mathrm{hr}$. Primary antibody (Rabbit Polyclonal MMP-11 from AbCam; 1:100) incubation was given for overnight at $4^{\circ} \mathrm{C}$. After extensive washwith 1X PBS, icubated with FITC conjugated secondary antibody (1:100) for $1 \mathrm{hr}$. Finally, propidium iodide $(1 \mu \mathrm{L} / 300 \mu \mathrm{L}$ of PBS) was added after PBS wash and cells were analyzed by fluorescence microscope.

\section{Western blot analysis}

Cellular protein extraction and SDS gel electrophoresis separation was performed as per (Teng et al., 2008). Primary antibodies: Rabbit-Paxillin of 1:500 (Cell signaling), mouse IgG anti-FAK antibody (AbCam) of 1:100 dilution and mouse-GAPDH of 1:1000 (ProteinTech) was used. Enhanced chemiluminescence detection was used to detect the protein signal by Western blot detection system (Biorad).

\section{In vitro cell culture assays}

In vitro cell proliferation and chemoresistance assays were performed as mentioned previously (Liu et al., 2012). For proliferation assay, cells were seeded in 96well plates (5000 cells/well) and incubated at $37^{\circ} \mathrm{C}$ for 24, 48 and 72 hours. Cell Counting Kit-8 (CCK-8) was used to measure cell viability at $450 \mathrm{~nm}$. In chemoresistance assay, cells were treated with 5-FU $(10 \mu \mathrm{g} / \mathrm{mL})$ and Cisplatin $(20 \mu \mathrm{mol} / \mathrm{L})$ and incubated for 48 hours. Subsequently, each well was supplemented with $10 \mu \mathrm{L}$ of Cell Counting Kit-8 (CCK-8) solution was added, incubated for 3 hours and $\mathrm{OD}_{450 \mathrm{~nm}}$ was measured. For cell migration assessment, Transwell chamber assay (Boyden chambers) was used. Briefly, cells were seed in upper chamber $\left(5 \times 10^{4}\right.$ cells/well $)$ in serum free medium, whereas the lower chamber was supplemented with $10 \%$ FBS. After 48 hours, the migrated cells adhered to basement membrane was counted by microscope at $200 \times$ magnification. Similarly, the matrigel invasion assay was carried out by matrigel invasion chambers (BD Biosciences, Shanghai). Cells were seed in serum free medium $\left(2 \times 10^{5}\right)$ and incubated for 48 hours. The noninvading cells are washed away whereas, the invaded cells are resided in the membrane which then subjected to microscopy for counting at $40 \times$.

\section{Statistical analysis}

The values represented in the quantification graph are mean \pm S.D. We have performed student's $t$-test to compare the significant differences between two groups. All $P$-values indicated are 2 sided and the $P$-value less than 0.05 were considered as statistically significant.

\section{RESULTS}

\section{Fluorescence activated cell sorting (FACs) analysis of side population cells in SCC-55 cell line.}

It has been previously reported that presence of side population (SP) cells in several solid cancers, which are responsible for the tumor relapse. In order to perform functional characterization of SP cells, we have used 

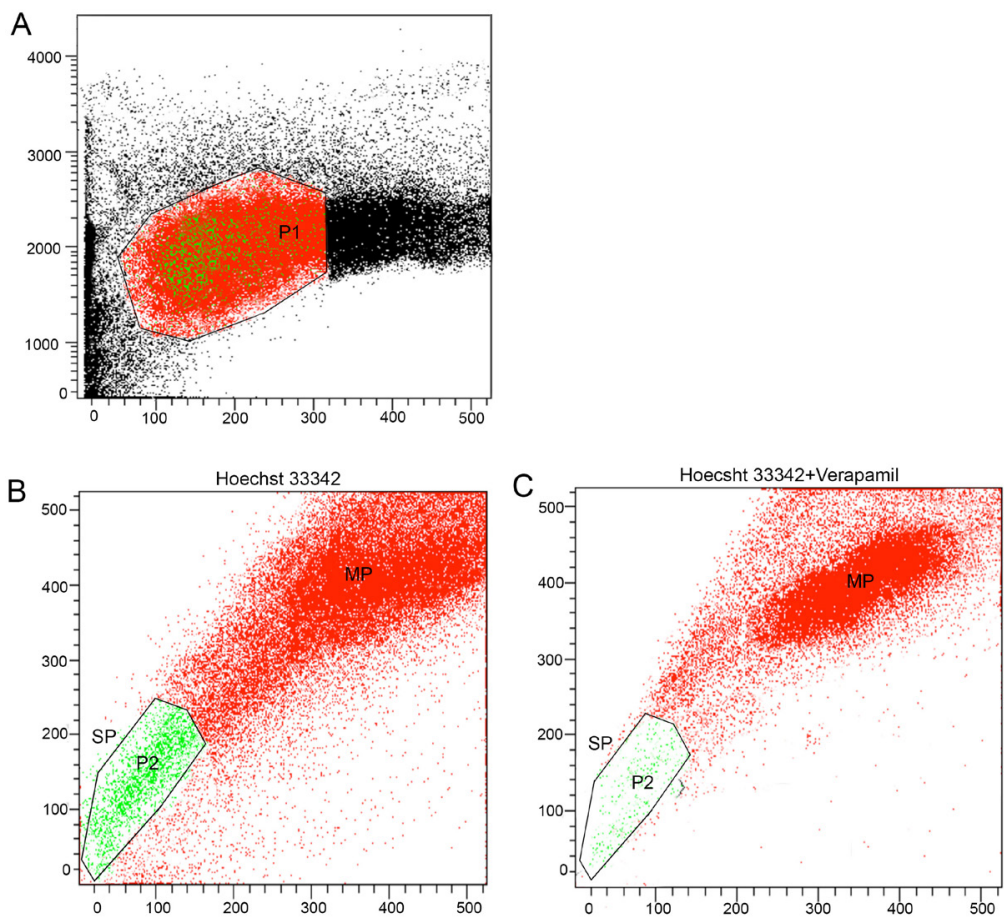

Figure 1. Side population cells in Oral Squamous Cell Carcinoma SCC-55 cell line.

(A) Dot plot analysis from FACs showing live cell population (P1gated region) by propidium iodide staining to exclude dead cells. (B) SCC-55 cells showing presence of $3.7 \%$ of side population (gated population) cells by Hoechst 33342 dye exclusion method. (C) Hoechst effluxing $3.7 \%$ cells in the P2 gated region was reduced to $0.5 \%$ on Verapamil treatment.

A
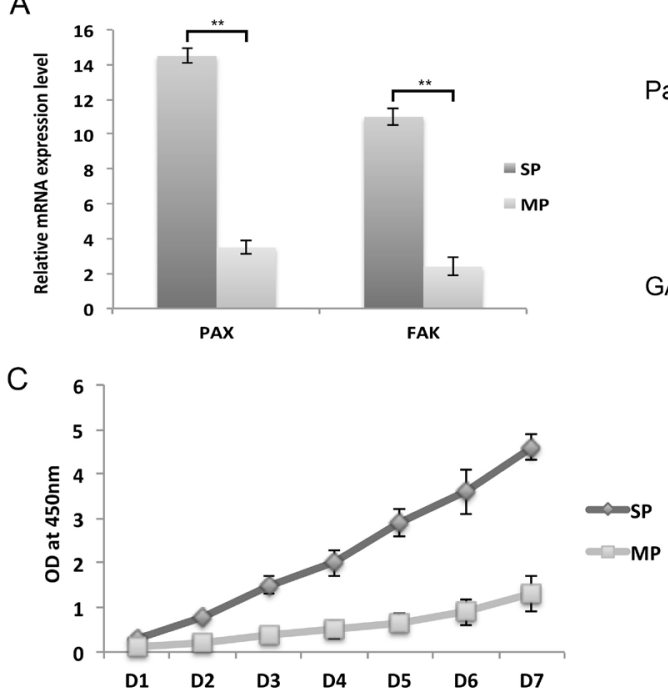

B

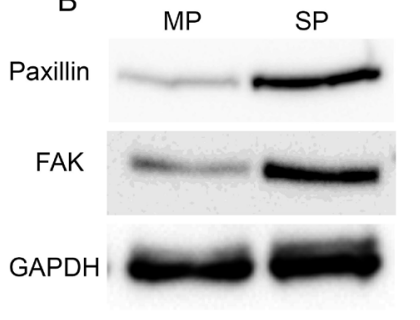

Figure 2. FAK and PXN upregulation in SCC-55 SP cells.

Quantification graph of RT-PCR analysis (A) and Western blot (B) showing the relative mRNA and protein expression are significantly accelerated in SP cells. C. In vitro cell proliferation assay revealed that SP cells are grows much faster than main population (MP) cells. The error bar is the standard deviation. ${ }^{*} P<0.03 ;{ }^{* *} P<0.01$.

oral squamous cell carcinoma (OSCC) cell line SCC-55. Previously, Liu et al showed the existence of SP cells in SCC-55 and they were phenotypically characterized for the expression pattern of cancer stem cell markers (Liu et al., 2005). In the present study, we have also employed FACs based Hoechst 33342 dye exclusion method to differentiate the SCC-55 SP and main population (MP) cells. By propidium iodide staining, we selected live cell population in the P1 gated region (Fig. 1A) by excluding the dead cells. From the gated P1 live cell population, we have identified and sorted $3.7 \%$ of SP cells (P2 gated in Fig. 1B), which can efficiently efflux the Hoechst 33342 dye on the side of the dot plot analysis. Several studies have been demonstrated that presence of multidrug resistance transporter-1 (MDR1), which belongs to the $\mathrm{ABC}$ transporter transmembrane proteins are actively involved in the drug expulsion process. However, the population of SP cells was significantly reduced to $0.5 \%$ being treated with verapamil (Fig. 1C), which can proficiently inhibit the function of $\mathrm{ABC}$ transporter proteins. 


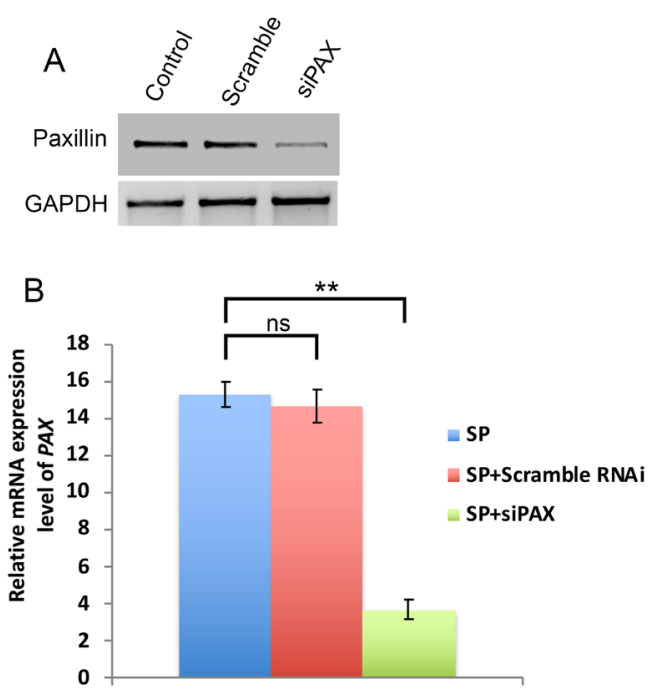

Figure 3. Silencing of PXN gene in SP cells of OSCC.

Western blot (A, B) and RT-PCR data showing that paxillin protein and its rate of mRNA transcription was significantly reduced in RNAi cells, when compared to control (non-transfected) and scramble RNAi transfected SP cells. The error bar is the standard deviation. ${ }^{*} P<0.01$.

\section{Expression profile of $F A K$ and paxillin in oral cancer SP cells}

It has been proved that overexpression of paxillin and FAK are associated with enhanced tumor invasion, migration potential, metastasis and resistance to cancer therapies (Owens et al., 1995; Sieg et al., 2000; Chen et al., 2013). Therefore, we made an assessment for PXN and FAK expression in oral cancer SP cells by RT-PCR. We found that relative mRNA expression level of $F A K$ and PXN are significantly stronger in SP cells (Fig. 2A). The oral cancer SP cells showed two-fold increase of PXN and FAK mRNA expression than MP cells. This result was further confirmed by western blot analysis, which showed again significantly higher expression profile of focal adhesion kinase and paxillin in SP cells (Fig. 2B). Therefore, the transcriptional upregulation of FAK and paxillin are consistent with the enhanced level of proteins synthesized in SP cells. Next, we have evaluated the growth rate between SP and MP cells. Figure 2C showing that SP cells can able to grow faster from D3 (day 3) onwards and have significantly higher growth rate till day 7 than MP cells, which grows very slowly. Therefore, we speculate that the enrichment of FAK and paxillin might be involved in faster proliferative potential of SP cells.

\section{Impact of paxillin knockdown on oral cancer invasion and migration}

As previously mentioned, over expression of paxillin and FAK are suggested to be involved increased invasion and migration potential. Therefore, we made an attempt to knock down the PXN expression in sorted $\mathrm{SP}$ cells by RNA interference (RNAi) method in order to determine their impact on cancer invasion and migration. By western blot (Fig. 3A and 3B) and RT-PCR analysis (Fig. 3C), we confirmed that paxillin expression is significantly downregulated in PXN depleted SP cells. However, there is no significant change in paxillin expression was observed in SP cells treated with scramble RNAi. In vitro matrigel assay revealed that SCC-55 SP cells have higher invasion potential than MP cells. None-

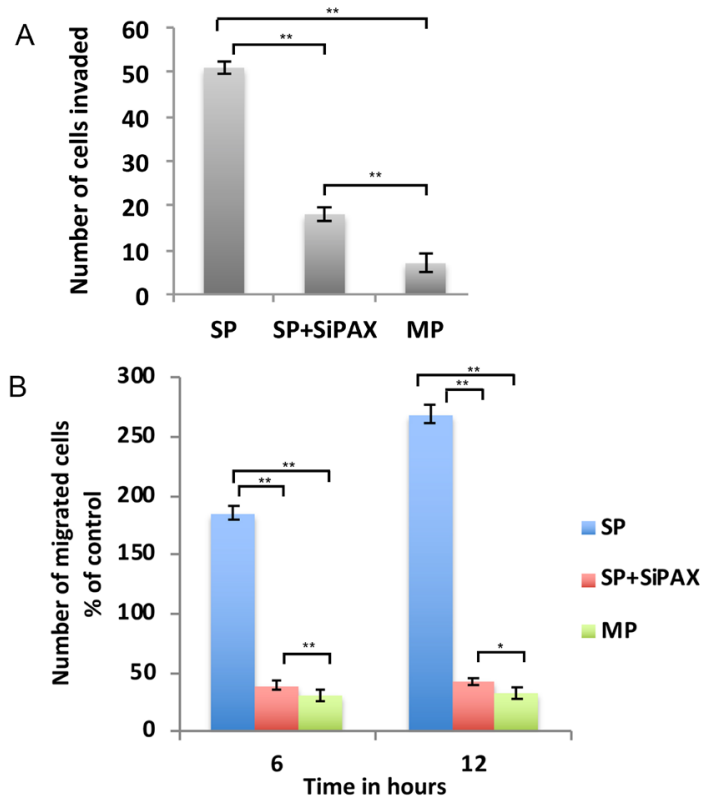

Figure 4. RNAi of Paxillin showed significant impact on cell invasion and migration.

Paxillin level in SP cells are depleted by using siRNA approach and cells were examined for invasion and migration potential. Down regulation of PXN in SP cells slow down the rate of cell invasion $(\mathbf{A})$ and motility $(\mathbf{B})$. The error bar is the standard deviation. ${ }^{*} P<0.04 ;{ }^{* *} P<0.01$.

theless, when the paxillin expression in depleted in SP cells, the efficiency of invasion property is significantly reduced to four-fold times (Fig. 4A). In addition, paxillin overexpressing SP cells possess increased rate of cell migration on soft agar assay. Upon siRNA transfection, cell migration efficiency was significantly reduced in siPAX SP cells (Fig. 4B). Therefore, these findings suggest that over expression of focal adhesion kinase and paxillin in $\mathrm{SP}$ cells promotes cancer cell invasion and migration.

\section{Attenuation of PXN expression restores sensitivity to cancer therapeutic drugs}

It has been documented that SP cells are highly resistance to chemotherapeutic drugs and that's the major cause for treatment failure and tumor recurrence. Therefore, we have performed chemoresistance assay between SP, SP+ siPAX and MP cells in order to determine whether the paxillin knock down influences the sensitivity of SP cells towards the anti-cancer drugs such as $5-\mathrm{FU}$ and Cisplatin. Interestingly, after siRNA transfection the SP cells showed increased sensitivity towards the 5-FU and Cisplatin (Fig. 5A) when compared to SP cells. Consequently, the cell viability and proliferation rate were significantly declined in PXN RNAi cells (Fig. 5B). Hence, treatment of anti-cancer drugs in combination with silencing of PXN showed more susceptibility towards the drug and thus may leads to activation of apoptosis so that the cell growth is declined.

\section{Elevated expression of MMP-11 in SCC-55 SP cells}

MMP-11 over expression was found to be associated with aggressive tumor phenotypes and poor survival of cancer patients (Porte et al., 1999; Fiorentino et al., 2009; Hsin et al., 2017). Hence, we have evaluated the expression of MMP-11 expression between SP and MP cells. 


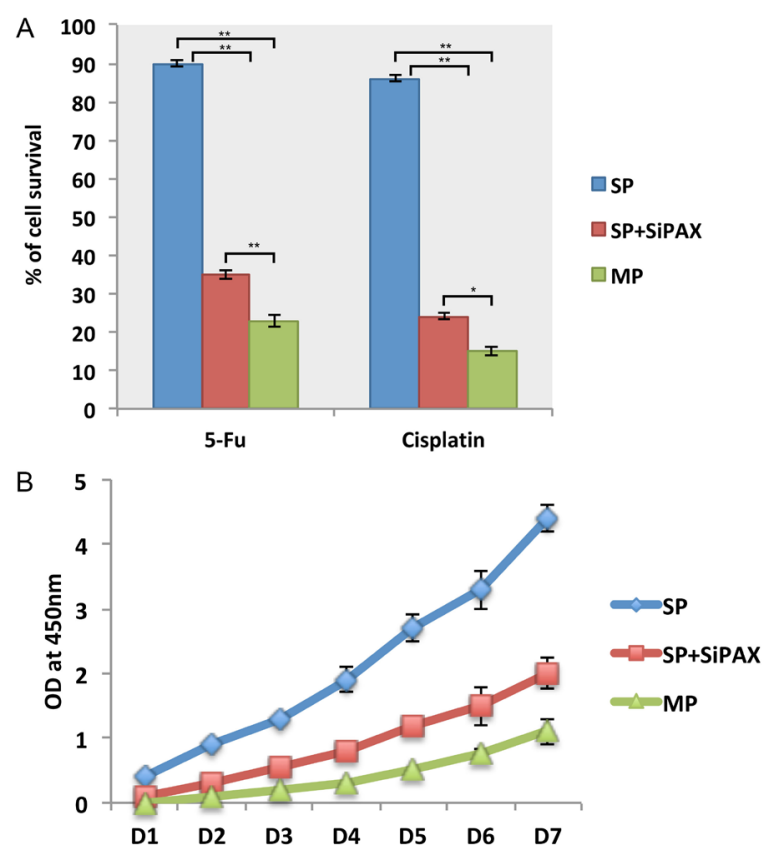

Figure 5. Downregulation of paxillin by siRNA increases the sensitivity to 5-FU and Cisplatin in SP cells.

(A) SP cells were transfected with PXN-siRNA and chemoresistance assay was performed. The siPAX SP cells showed increased sensitivity to 5-FU and Cisplatin and therefore the cell growth rate (B) was significantly reduced in siPAX cells. The error bar is the standard deviation. ${ }^{*} P<0.02 ;{ }^{*} P<0.01$

Western blot analysis (Fig. 6A) showing that SP cells have elevated expression of MMP-11 than MP cells. Consistently, SP cells displayed transcriptional upregulation for MMP-11 in SP cells of OSCC (Fig. 6B). Taken together, higher expression profile of MMP-11, FAK and paxillin might collectively promote oral cancer invasion and migration.

\section{DISCUSSION}

Cytoskeletal organization is important for cell motility. The formation of actin cytoskeleton in the well-formed lamellipodia and filopodia structures direct the cells to move along the basement membrane (Lauffenburger, 1996). In cancerous cells, the cytoskeletal organization is disrupted so they have increased cell motility, whereas the normal cells are firmly attached. It has been shown that changes in the level of F-actin leads to disruption of cytoskeleton integrity in metastatic cancers (Bernal et al., 1983).

Paxillin is a $68 \mathrm{KDa}$ protein localizes to focal adhesion and it has been shown to interact with integrins, growth factors and few oncoproteins as well. It has N-terminus interaction sites for proteins have $\mathrm{SH} 2 / \mathrm{SH} 3$ domains and a C-terminus LIM domain (Turner et al., 1994). In response to many stimuli, paxillin can be phosphorylated at tyrosine residue, which facilitates the interaction of paxillin with several other proteins at focal adhesions site (Schaller et al., 1995). It has been demonstrated that strong and enhanced paxillin expression in different cancers such as lung, prostrate, bone and colorectal cancers, ultimately cause accelerated cell proliferation, invasion and migration (Schaller et al., 1995; Chen et al., 2013). In contrast, neither over nor under expression of paxil-
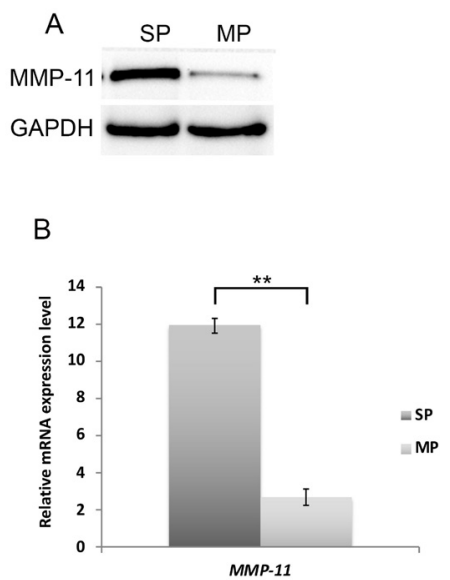

Figure 6. Evaluation of MMP-11 expression level in SCC-55 SP cells.

Western blot analysis (A) RT-PCR (B) showing over expression of MMP-11 protein in SP cells than MP cells. The scale bar is $10 \mu \mathrm{m}$. The error bar is the standard deviation. ${ }^{* *} P<0.01$.

lin was observed in squamous and large cell lung cancer (Salgia et al., 1999) when compared to control ones.

Studies in colon cancer demonstrated that over expression of paxillin cause cetuximab resistance and silencing of PXN makes cancer cells more sensitive towards cetuximab. The improvement in chemo sensitivity was executed by the inactivation of p-Erk pathway (Du et al., 2016). Similarly, we also observed that chemotherapeutic drugs (5-FU and cisplatin) in combination with knock down of PXN improve sensitivity of oral cancer SP cells to the drugs. Several studies focussed on the possible relationship between chemo resistance, apoptosis and autophagy induction in tumor cells. Apoptosis downregulation and chemoresistance are consistent with increased autophagy induction (Çoker-Gürkan et al., 2015). Treatment of drugs in combination with autophagy inhibitors would definitely improve the efficacy of chemotherapy in cancer patients ( $\mathrm{Li}$ et al., 2009). Altogether, chemoresistance of oral cancer SP cells are possibly mediated by elevated level of paxillin whose downregulation significantly overcome the drug resistance.

Members of MMPs such as MMP-1, MMP-2, MMP9 and MMP-11 are over expressed in tumor tissues/ cells and they have been implicated in cancer progression (Rosenthal et al., 2006). OSCC tissues were showed intense positive staining and over expressed MMP-11 which are correlated with metastatic stage (Soni et al., 2003) but not with the patients survival rate. But the recent study by Hsin et al., showed that tumor aggressiveness and modest survival rate of OSCC patients are coupled with MMP-11 strong expression (Hsin et al., 2017). Thus, MMP-11 over expression is considered as an indicator for the progression from neoplasm to malignancy. Further, MMP-11 activates FAK and Src pathways which are highly capable of regulating cancer cell migration and invasion (Lee et al., 2015; Cheng et al., 2016). Similar to paxillin, MMP-11 over expressed cells showed increased phosphorylation rate of FAK and src, crucial for promoting cancer cell migration, metastasis and angiogenesis (Hsin et al., 2017).

In summary, we observed that focal adhesion proteins such as paxillin and FAK are highly expressed in SP cells of oral cancer cell line SCC-55. Similarly, the MMP11 protein levels are upregulated in the SP cells, which may be the ultimate cause for the activation of FAK 
and paxillin mediated signalling pathways to promote cell migration and metastasis. Further, the knockdown of PXN by RNA interference significantly reduces the rate of chemoresistance, cell proliferation, invasion and migration potential. In line with the previous findings, our data suggest that strong expression of FAK, paxillin and MMP-11 are combinedly associated with increased incidence of oral cancer metastasis. However, the limitations of our investigation are the lack of in vivo examinations, which needs to study further in detail.

Therefore, in addition to conventional clinical (tumor side, shape and differentiation pattern) and pathological biomarkers (oncogene expression, tumor suppressors, proliferative and metastatic markers), paxillin expression could be used as a potential prognostic factor to determine the aggressiveness of tumor types. In future, it is worth to investigate the specific region of FAK and paxillin, which are promoting dynamics of invasion and migration. This could be achieved by site/point based mutation and/or protein truncation to functionally characterize them. Further detailed study of these factors and underlying mechanisms in oral cancer will paves a way to improve the patients susceptibility towards the developed novel therapeutic agents.

\section{Conflict of interest}

All authors declared no conflict of interest.

\section{REFERENCES}

Agochiya M, Brunton VG, Owens DW, Parkinson EK, Paraskeva C, Keith WN, Frame MC (1999) Increased dosage and amplification of the focal adhesion kinase gene in human cancer cells. Oncogene 18: 5646-5653. https://doi.org/10.1038/sj.onc.1202957

Aguirre Ghiso JA (2002) Inhibition of FAK signalling activated by urokinase receptor induces dormancy in human carcinoma cells in vivo. Oncogene 21: 2513-2524. https://doi.org/10.1038/sj.onc.1205342

Bernal SD, Baylin SB, Shaper JH, Gazdar AF, Chen LB (1983) Cytoskeleton-associated proteins of human lung cancer cells. Cancer Res 4: 1798-17808. https://doi.org/10.1016/j.ajpath.2018.03.007

Bernier J, Domenge C, Ozsahin M, Matuszewska K, Lefebvre JL, Greiner RH, Giralt J, Maingon P, Rolland F, Bolla M, Cognetti F, Bourhis J, Kirkpatrick A, van Glabbeke M (2004) Postoperative irradiation with or without concomitant chemotherapy for locally advanced head and neck cancer. $N$ Engl I Med 350: 1945-1952. https://doi.org/10.1056/NEJMoa032641

Chen DL, Wang ZQ, Ren C, Zeng ZL, Wang DS, Luo HY, Wang F, Qiu MZ, Bai L, Zhang DS, Wang FH (2013) Abnormal expression of paxillin correlates with tumor progression and poor survival in patients with gastric cancer. J Transl Med 1: 277. https://doi. org/0.1186/1479-5876-11-277

Chen DL, Wang DS, Wu WJ, Zeng ZL, Luo HY, Qiu MZ, Ren C, Zhang DS, Wang ZQ, Wang FH, Li YH (2013) Overexpression of paxillin induced by miR-137 suppression promotes tumor progression and metastasis in colorectal cancer. Carcinogenesis 34: 803-811. https://doi.org/ 10.1093/carcin/bgs400

Cheng HL, Lin CW, Yang JS, Hsieh MJ, Yang SF, Lu KH (2016) Zoledronate blocks geranylgeranylation not farnesylation to suppress human osteosarcoma U2OS cells metastasis by EMT via Rho $\mathrm{A}$ activation and FAK-inhibited $\mathrm{JNK}$ and $\mathrm{p} 38$ pathways. Oncotarget 7: 9742-9758. https://doi.org/10.18632/oncotarget.7138

Coker-Gürkan A, Arisan ED, Obakan P, Palavan-Unsal N (2015) Lack of functional p53 renders DENSpm-induced autophagy and apoptosis in time dependent manner in colon cancer cells. Amino Acids 47: 87-100. https://doi.org/10.1007/s00726-014-1851-7

Du C, Wang X, Zhang J, Liu X, Zhu J, Liu Y (2016) Paxillin is positively correlated with the clinicopathological factors of colorectal cancer, and knockdown of Paxillin improves sensitivity to cetuximab in colorectal cancer cells. Oncol Rep 35: 409-417. https://doi. org/10.3892/or.2015.4352

Fiorentino M, Fu L, Shi YB (2009) Mutational analysis of the cleavage of the cancer-associated laminin receptor by stromelysin-3 reveals the contribution of flanking sequences to site recognition and cleavage efficiency. Int J Mol Med 23: 389-397. https://doi.org/10.3892/ ijmm_00000143
Frisch SM, Vuori K, Ruoslahti E, Chan-Hui PY (1996) Control of adhesion-dependent cell survival by focal adhesion kinase. J Cell Biol 134: 793-799. https://doi.org/10.1083/jcb.134.3.793

Hagel M, George EL, Kim A, Tamimi R, Opitz SL, Turner CE, Imamoto A, Thomas SM (2002) The adaptor protein paxillin is essential for normal development in the mouse and is a critical transducer of fibronectin signaling. Mol Cell Biol 22: 901-915. https:// doi.org/10.1128/mcb.22.3.901-915.2002

Hong S, Lee JB, Iizuka Y, Song YK, Seong GJ, Han SH (2012) The role of focal adhesion kinase in the TGF- $\beta$-induced myofibroblast transdifferentiation of human Tenon's fibroblasts. Korean J OphthalmolF 1: 45-48. https://doi.org/10.3341/kjo.2012.26.1.45

Hsin CH, Chou YE, Yang SF, Su SC, Chuang YT, Lin SH, Lin CW (2017) MMP-11 promoted the oral cancer migration and Fak/Src activation. Oncotarget 20: 32783-32793. https://doi.org/10.18632/ oncotarget.15824

Jun Q, Zhiwei W, Lilin M, Jing K, Qichao N (1995) Effects of paxillin on HCT-8 human colorectal cancer cells. Hepatogastroenterology 58: 1951-1955. https://doi.org/10.5754/hge11352

Jagadeeswaran R, Surawska H, Krishnaswamy S, Janamanchi V, Mackinnon AC, Seiwert TY, Loganathan S, Kanteti R, Reichman T, Nallasura V, Schwartz S (2008) Paxillin is a target for somatic mutations in lung cancer: Implications for cell growth and invasion. Cancer Res 68: 132-142. https://doi.org/10.1158/0008-5472.CAN07-1998

Lauffenburger DA (1996) Cell motility. Making connections count. Nature 6599: 390-391. https://doi.org/10.1038/383390a0

Lee BY, Timpson P, Horvath LG, Daly RJ (2015) FAK signaling in human cancer as a target for therapeutics. Pharmacol Ther 146: 132149. https://doi.org/10.1016/j.pharmthera.2014.10.001

Li D, Ding J, Wang X, Wang C, Wu T (2009) Fibronectin promotes tyrosine phosphorylation of paxillin and cell invasiveness in the gastric cancer cell line AGS. Tumori 95: 769-779

Li J, Hou N, Faried A, Tsutsumi S, Takeuchi T, Kuwano H (2009) Inhibition of autophagy by 3-MA enhances the effect of 5-FU-induced apoptosis in colon cancer cells. Ann Surg Oncol 16: 761-771. https://doi.org/10.1245/s10434-008-0260-0

Lin CW, Yang WE, Lee WJ, Hua KT, Hsieh FK, Hsiao M, Chen CC, Chow JM, Chen MK, Yang SF, Chien MH (2016) Lipocalin 2 prevents oral cancer metastasis through carbonic anhydrase IX inhibition and is associated with favourable prognosis. Carcinogenesis 37: 712-722. https://doi.org/10.1093/carcin/bgw050

Liu Y, Cui P, Chen J, Li W (2015) Isolation and phenotypic characterization of side population cells in oral squamous cell carcinoma. Mol Med Rep 5: 3642-3646. https://doi.org/10.3892/mmr.2014.3133

Owens LV, Xu L, Craven RJ, Dent GA, Weiner TM, Kornberg L, Liu ET, Cance WG (1995) Overexpression of the focal adhesion kinase (p125 $5^{\mathrm{FAK}}$ ) in invasive human tumours. Cancer Res 55: 2752-5257. PMID: 7796399

Porte H, Chastre E, Prevot S, Nordlinger B, Empereur S, Basset P, Chambon P, Gespach C (1995) Neoplastic progression of human colorectal cancer is associated with overexpression of the stromelysin-3 and BM-40/SPARC genes. Int J Cancer 64: 70-75. https://doi. org/10.1002/ijc.2910640114

Rosanò L, Spinella F, Di Castro V, Nicotra MR, Albini A, Natali PG, Bagnato A (2003) Endothelin receptor blockade inhibits molecular effectors of Kaposi's sarcoma cell invasion and tumor growth in vivo. Am J Pathol 163: 753-762. https://doi.org/10.1016/S00029440(10)63702-9

Rosenthal EL, Matrisian LM (2006) Matrix metalloproteases in head and neck cancer. Head Neck 28: 639-648. https://doi.org/10.1002/ hed.20365

Salgia R, Li JL, Ewaniuk DS, Wang YB, Sattler M, Chen WC, Richards W, Pisick E, Shapiro GI, Rollins BJ, Chen LB, Griffin JD, Sugarbaker DJ (1999) Expression of the focal adhesion protein paxillin in lung cancer and its relation to cell motility. Oncogene 1: 67-77. https://doi.org/10.1038/sj.onc.1202273

Schaller MD, Borgmana CA, Cobb BS, Vines RR, Reynolds AB, Parsons JT (1992) pp125FAK, a structurally unique protein tyrosine kinase associated with focal adhesions. Proc Natl Acad Sci U S A 89: 5192-5196. https://doi.org/10.1083/jcb.132.1.211

Schaller MD, Otey CA, Hildebrand JD, Parsons JT (1995) Focal adhesion kinase and paxillin bind to peptides mimicking beta integrin cytoplasmic domains. J Cell Biol 5: 1181-1187. https://doi. org/10.1083/jcb.130.5.1181

Shekhar S, Angadi PV (2017) Evaluation of paxillin expression in patients with oral squamous cell carcinoma: An immunohistochemical study. J Oral Maxillofac Pathol 21: 318-319. https://doi.org/10.4103/ jomfp.JOMFP_98_17

Sieg DJ, Hauck $\bar{C}$, Ilic D, Klingbeil CK, Schaefer E, Damsky CH, Schlaepfer DD (2000) FAK integrates growth factor and integrin signals to promote cell migration. Nat Cell Biol 2: 249-256. https:// doi.org/10.1038/35010517

Soni S, Mathur M, Shukla NK, Deo SV, Ralhan R (2003) Stromelysin-3 expression is an early event in human oral tumorigenesis. Int $J$ Cancer 107: 309-316. https://doi.org/10.1002/ijc.11366 
Su SC, Hsieh MJ, Yang WE, Chung WH, Reiter RJ, Yang SF (2017) Cancer metastasis: Mechanisms of inhibition by melatonin. I Pineal Res 62 (1). https://doi.org/10.1111/jpi.12370

Teng KY, Qiu MZ, Li ZH, Luo HY, Zeng ZL, Luo RZ, Zhang HZ, Wang ZQ, Li YH, Xu RH (2010) DNA polymerase eta protein expression predicts treatment response and survival of metastatic gastric adenocarcinoma patients treated with oxaliplatin-based chemotherapy. J Transl Med 8: 126. https://doi.org/10.1186/1479-5876-8126

Tremblay L, Hauck W, Aprikian AG, Begin LR, Chapdelaine A, Chevalier S (1996) Focal adhesion kinase (pp125FAK) expression, activation and association with paxillin and p50CSK in human metastatic prostate carcinoma. Int J Cancer 68: 164-71. https://doi. org/10.1002/(sici)1097-0215(19961009)68:2<169::aid-ijc4>3.0.co;2-w

Turner CE, Miller JT (1994) Primary sequence of paxillin contains putative $\mathrm{SH} 2$ and $\mathrm{SH} 3$ domain binding motifs and multiple LIM do- mains: identification of a vinculin and pp125Fak-binding region. $J$ Cell Sci 6: 1583-1591. PMID: 7525621

Turner CE (2000) Paxillin interactions. J Cell Sci 113: 4139-4140. PMID: 11069756

Vadlamudi R, Adam L, Tseng B, Costa L, Kumar R (1999) Transcriptional up-regulation of paxillin expression by heregulin in human breast cancer cells. Cancer Res 59: 2843-2846. PMID: 10383144

Wolff JM, Zimny M, Borchers H, Wildberger J, Buell U, Jakse G (1998) Is prostate-specific antigen a reliable marker of bone metastasis in patients with newly diagnosed cancer of the prostate? Eur Urol 33: 376-381. https://doi.org/10.1159/000019619

Zini A, Czerninski R, Sgan-Cohen HD (2010) Oral cancer over four decades: epidemiology, trends, histology, and survival by anatomical sites. J Oral Pathol Med 39: 299-3057. https://doi.org/10.1111/ j.1600-0714.2009.00845.x 